\title{
A Closer Look at the Preclinical Experience of RP5063 in Pulmonary Arterial Hypertension Laxminarayan Bhat $^{*}$ and Dany Salvail ${ }^{2}$ \\ 'Reviva Pharmaceuticals, Inc., Santa Clara, CA, USA \\ IIPS Therapeutique Inc., Sherbrooke, Quebec, Canada
}

Article Info

\section{Article Notes}

Received: July 08, 2017

Accepted: August 07, 2017

\section{*Correspondence:}

Dr. Laxminarayan Bhat

3900 Freedom Cr. Suite 101, Santa Clara, CA 95054, USA

Tel: +1 (408) 816.1454; Fax: +1 4089046270

Email: Ibhat@revivapharma.com

C 2017 Bhat L. This article is distributed under the terms of the Creative Commons Attribution 4.0 International License.

\section{ABSTRACT}

Pulmonary arterial hypertension (PAH) is a chronic, debilitating condition with a 5- to 7-year survival rate of approximately $50 \%$ following diagnosis. It is defined by pulmonary vasculature constriction and remodeling, and its pathobiology involves dysfunctional signaling of the serotonin (5-HT) receptors, $5-\mathrm{HT}_{2 \mathrm{~A} / 2 \mathrm{~B} / 7}$ in the pulmonary arteries. RP5063 is a novel, multimodal dopamine (D)-serotonin (5-HT) stabilizer with partial agonist activity for $D_{2 / 3 / 4}$ and $5-\mathrm{HT}_{1 \mathrm{~A} / 2 \mathrm{~A}^{\prime}}$ antagonist activity for $5-\mathrm{HT}_{2 \mathrm{~B} / 2 \mathrm{C} / 6 / 7}$ and moderate affinity for the serotonin transporter (SERT). It received orphan status by the US Food and Drug Administration in 2016 to treat PAH. Two recent preclinical studies evaluated the effectiveness of RP5063 in PAH-induced rat models. The monocrotaline (MCT)-induced PAH model involved treatment with RP5063 (1, 3, and $10 \mathrm{mg} / \mathrm{kg}$ twice daily [BID]) over 28 days. The Sugen-hypoxia ( $\mathrm{SuHx}$ )-induced PAH model involved treatment with RP5063 (10 and $20 \mathrm{mg} / \mathrm{kg}$ BID) over 21 days starting at Day 14 following induction. Both models demonstrated that RP5063 promoted significant functional improvements and structural changes in the pulmonary vasculature. RP5063 limited induced increases of proinflammatory cytokines in the MCT model, and limited leukotriene B4 levels, arterial obliteration, and prevented plexiform lesion formation in the SuHx model. A follow on MCT study, examining the effectiveness of RP5063 alone and in combination with standard treatments, corroborated these single-agent data and helped to define the framework for the clinical development of this compound. This review explores these studies, their underlying nuances, and the underlying pharmacologic rationale for the effects produced by RP5063.

\section{Introduction}

RP5063 is a novel dopamine (D)-serotonin (5-HT) stabilizer with partial agonist activity of $\mathrm{D}_{2 / 3 / 4}, 5-\mathrm{HT}_{1 \mathrm{~A} / 2 \mathrm{~A}}$, antagonist activity of $5-\mathrm{HT}_{2 \mathrm{~B} / 2 \mathrm{C} / 6 / 7}$ receptors, and moderate affinity for serotonin transporter (SERT) ${ }^{1}$. The compound already brings established efficacy, safety, and pharmacokinetic profiles based on data from a Phase 1 evaluation in normal healthy individuals and patients with stable schizophrenia, and a Phase 2 study of patients with acute schizophrenia and schizoaffective disorder ${ }^{1}$.

Two preclinical studies, recently published in the European Journal of Pharmacology, evaluated the effectiveness of RP5063 in pulmonary arterial hypertension (PAH), a chronic, debilitating condition that affects approximately 17,500 Americans (1: 20,000 prevalence) every year ${ }^{2-4}$. Both studies demonstrated that RP5063 reduced the structural and functional effects of monocrotaline (MCT)- and Sugen-hypoxia (SuHx)-induced PAH in rats. They also provided initial, exploratory insights into several anticytokine/ 
chemokine effects with this compound. These studies were notable due to the existing need for newer strategies to address the underlying pathology (cytoproliferation and vascular remodeling) of PAH, a condition that has eluded successful treatment and is associated with Kaplan-Meier 5- to 7 -year survival rate estimates of $57 \%$ and $49 \%$, respectively, following diagnosis ${ }^{5,6}$.

This review examines the preclinical experience with RP5063 for pulmonary arterial hypertension, the nuances of the 2 PAH models used, and underlying pharmacologic effects relevant to the effectiveness of this compound in $\mathrm{PAH}$.

\section{RP5063 MCT and SuHx Study Highlights}

The MCT-induced PAH model involved a 28-day treatment with single-agent RP5063 ${ }^{2}$. On Day 0 , a single 60$\mathrm{mg} / \mathrm{kg}$ MCT dose was injected into adult male Wistar-Kyoto rats, which were randomized into 5 groups of 10 animals. On Days 0 to 27, rats induced with MCT were gavaged twice daily (BID) with vehicle (Veh;5\% glucose solution), RP5063 (1, 3, or $10 \mathrm{mg} / \mathrm{kg}$; RP-1, RP-3, RP-10, respectively), or sildenafil (50 mg/kg; SIL-50). On Day 28, terminal surgery was performed, and blood samples, hemodynamic readings, and harvested tissues were obtained.

RP5063 produced significant functional and structural effects (Table 1), as compared with those seen in the Veh group ${ }^{2}$. Functionally, RP-10 and SIL-50 maintained healthier pulmonary hemodynamics. These effects translated to reduced right ventricle (RV) hypertrophy, suggesting greater pulmonary vascular elasticity. RP5063 also appeared to prevent the remodeling. This activity led to greater respiratory resistance and lower hemoglobin oxygen saturation in PAH animals. Structurally, RP-10 and SIL-50 prevented vascular intimal thickening (endothelial and smooth muscle hyperplasia, and the multiplication of vascular smooth muscle cells) in the smaller vessels, which are largely non-muscular in healthy animals. In the exploring cytokine response (Figure 1), all doses of RP5063 resulted in lower levels of tumor necrosis factor (TNF) $\alpha$ and interleukin (IL) $\beta$, and they promoted a significant reduction of IL-6 $(\mathrm{p}<0.05)$.

Table 1. Effect of RP5063 on MCT-induced PAH in rats ${ }^{2}$

\begin{tabular}{|c|c|c|c|c|}
\hline \multirow[t]{2}{*}{ Parameter } & \multirow[t]{2}{*}{ Healthy animals } & \multicolumn{3}{|c|}{ MCT-induced PAH Treatments } \\
\hline & & Vehicle & $\begin{array}{c}\text { RP5063 } \\
10 \mathrm{mg} / \mathrm{kg} / \\
\text { BID }\end{array}$ & $\begin{array}{c}\text { Sildenafil } \\
50 \mathrm{mg} / \mathrm{kg} \\
\text { BID }\end{array}$ \\
\hline Diastolic pulmonary pressure (mmHg) & 11.4 & 21.1 & 14.7 & 16.6 \\
\hline Systolic pulmonary pressure (mmHg) & 26.7 & 64.0 & 43.0 & 43.0 \\
\hline Mean pulmonary pressure (mmHg) & 16.5 & 35.4 & 24.1 & 25.5 \\
\hline Respiratory resistance $(\mathrm{mmHg} / \mathrm{mL} / \mathrm{s})$ & 11.7 & 20.9 & 10.7 & 11.1 \\
\hline Fulton's index & 0.3 & 0.5 & 0.3 & 0.4 \\
\hline Small vessel wall thickness (\%) & 16.7 & 41.9 & 25.3 & 22.9 \\
\hline Presence of vascular smooth muscle (\%) & 11.1 & 81.2 & 47.5 & 40.0 \\
\hline
\end{tabular}

IL-1 $\beta$

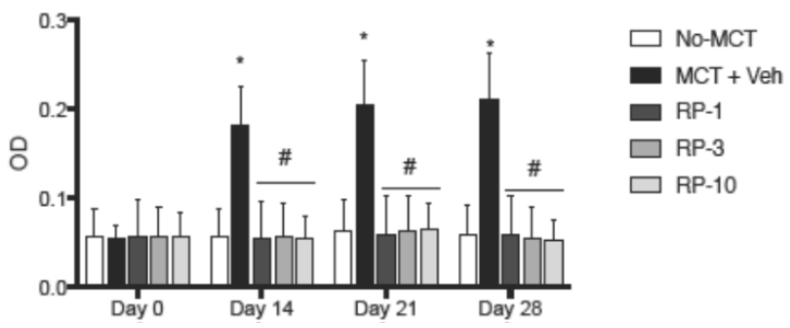

IL-6

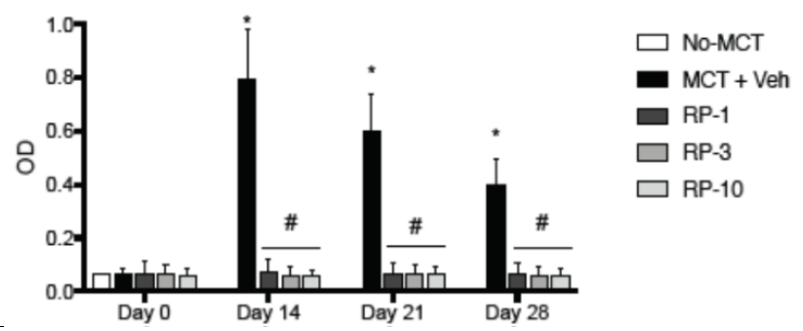

Figure 1. Cytokine release in MCT-induced PAH in rats ${ }^{2}$

MCT-induced PAH is characterized by an early inflammatory component initiated by TNF- $\alpha$ release, followed by sustained elevated levels of IL-1 $\beta$ and IL-6. When plasma was harvested from PAH animals in a MCT study, levels of IL-1 $\beta$ and IL- 6 rose before Day 14 postinduction. Increasing doses of RP5063 significantly prevented the initial, inflammatory phase of the disease, which may have contributed to the significant preventive efficacy of RP5063 against MCT-induced PAH in rats. Sildenafil data were not included due to limited samples and inconsistent data during this exploratory investigation into effects upon inflammatory cytokine release.

* P < 0.05; as compared to No-MCT. \# P < 0.05; as compared to MCT+Veh. No-MCT - control animals no MCT, MCT+Veh - MCT-induced rats + vehicle, RP-1, -3, and -10 - MCT-induced rats treated with RP5063 at 1, 3 and $10 \mathrm{mg} / \mathrm{kg}$ b.i.d., MCT-induced rats treated with sildenafil $50 \mathrm{mg} / \mathrm{kg}$ b.i.d.(Sil-50)., IL - interleukin, OD - optical density value, TNF - tumor necrosis factor.

Reprinted from Eur J Pharmacol., Vol 810, Bhat L, et al. RP5063, a novel, multimodal, serotonin receptor modulator, prevents monocrotaline-induced pulmonary arterial hypertension in rats. Pages No. 92-99, Copyright (2017), with permission from Elsevier. 
The SuHx-induced PAH study involved treatment for 21 days $^{3}$. On Day 0, Sugen $5416(20 \mathrm{mg} / \mathrm{kg})$ was administered subcutaneously to 4 groups of adult male Wistar-Kyoto rats kept at $\mathrm{FiO}_{2}$ of $10 \%$ (Days $0-21$ ) and 21\% (Days 22-35). These SuHx-induced rats were gavaged BID with vehicle (Veh; 5\% glucose solution), RP5063 (10 or $20 \mathrm{mg} /$ $\mathrm{kg}$; RP-10 and RP-20, respectively), or SIL-50 on Days 14 to 35. Terminal surgery was performed, and blood samples, hemodynamic readings, and harvested tissues were obtained (Day 35).

Both doses of RP5063 and sildenafil demonstrated a significant effect on functional and structural parameters (Table 2), as compared with the induced group treated with vehicle (Veh). Functionally, treatment with RP5063 resulted in improved pulmonary hemodynamics and respiratory function, with higher oxygen saturation measured in treated animals, compared to non-treated, but sick animals. Structurally, RP5063 reduced small-vessel wall thickness and the percentage of muscular vessels. Based on micrographic evidence, they also limited arterial obliteration and, most notably, prevented the formation of plexiform lesions. Both RP5063 dose groups reflect lower levels of LT-B4 at Days 21, 28, and 35.

\section{Role of 5-HT Modulation}

5 -HT is unique in that it can cause endothelial disruption and platelet stimulation at concentrations not much higher than resting levels in mammalian blood ${ }^{7}$. Interestingly, the synthesis of 5-HT occurs outside of the central nervous system, primarily in the enterochromaffin cells of the gastrointestinal tract and the endothelial cells of the pulmonary artery ${ }^{8}$. It is a mitogen of human and rat cell types, such as pulmonary endothelial and smooth muscle cells ${ }^{9}$.

5-HT plays a role in both the proliferative and functional components of the pathogenesis of $\mathrm{PAH}^{9-11}$. Changes in 5-HT synthesis, receptor activation, and uptake via SERT are noteworthy ${ }^{10,11}$. Increased levels of 5 -HT mediate their local actions within the pulmonary vasculature through $5-\mathrm{HT}_{1 \mathrm{~B} / 2 \mathrm{~A} / 2 \mathrm{~B} / 7}$ and SERT ${ }^{12,13}$. Expression of SERT, $5-\mathrm{HT}_{1 \mathrm{~B} / 2 \mathrm{~B}^{\mathrm{B}}}$, and tryptophan hydroxylase 1 is enhanced in the pulmonary artery smooth-muscle and endothelial cells observed in $\mathrm{PAH}^{11,14,15}$. The presence of 5 -HT in the pulmonary circulation activates vascular smooth muscle, $5-\mathrm{HT}_{2 \mathrm{~A} / 2 \mathrm{~B} / 7}$ receptors, and SERT to cause constriction and proliferation of pulmonary vascular smooth-muscle cell $s^{6,14}$. These interactions facilitate vascular constriction and the proliferation of pulmonary artery smooth muscle cells and fibroblasts ${ }^{16}$. Coupled with the stimulation of the transforming growth factor $\beta$ pathway, the 5-HT pathway facilitates cell proliferation and vascular remodeling ${ }^{15}$. These changes lead to the thickening of the medial layer, along with the narrowing and the remodeling of pulmonary arteries - all of which define the characteristics of PAH.

Furthermore, the RP5063 preclinical studies build on the growing body of evidence that suggests that the targeting of the $5-\mathrm{HT}_{2 \mathrm{~A} / 2 \mathrm{~B} / 7}$ receptors can impact the pathology of $\mathrm{PAH}^{14,16-18}$. The targeting of the $5-\mathrm{HT}_{2 \mathrm{~B}}$ receptor specifically can reduce inflammatory cell recruitment to the lungs, pulmonary arterial smooth muscle muscularization and thickening, vascular stiffness, remodeling, pulmonary arterial pressure, and RV hypertrophy ${ }^{10,13,17,18}$.

Antagonism of these receptors has been shown to prevent PAH in animals ${ }^{10,14,17,18}$. In a BMPR2-mutant mouse model, SB204741, a small molecule 5- $\mathrm{HT}_{2 \mathrm{~B}}$ receptor antagonist, reduced inflammatory cell recruitment to the lungs, pulmonary artery smooth muscle muscularization, and vascular stiffness by limiting the effects of 5-HT on Src tyrosine kinase activity and downstream activity ${ }^{10}$. These combined effects prevented the development of PAH in heritable disease ${ }^{10}$. In a MCT rat model of PAH, the long-term use of terguride, a potent $5-\mathrm{HT}_{2 \mathrm{~A} / 2 \mathrm{~B}}$ receptor antagonist approved for ovulation disorders, inhibited the proliferation of pulmonary artery smooth muscle cells, abolished 5-HT-induced pulmonary vasoconstriction, and limited RV systolic pressure, hypertrophy, and disease progression $^{14}$. In another MCT rat model study, PRX08066, a $5-\mathrm{HT}_{2 \mathrm{~B}}$-specific receptor antagonist, attenuated vascular remodeling, decreased elevated pulmonary arterial pressure, and reduced RV hypertrophy ${ }^{18}$. The peroxisome proliferator-activated receptor $\gamma$ agonist, rosiglitazone, reversed the expression and vasoconstrictive effect and

Table 2. Effect of RP5063 on Sugen-hypoxia-induced PAH in rats ${ }^{3}$

\begin{tabular}{|c|c|c|c|c|c|}
\hline \multirow[t]{2}{*}{ Parameter } & \multirow[t]{2}{*}{$\begin{array}{l}\text { Healthy } \\
\text { animals }\end{array}$} & \multicolumn{4}{|c|}{$\frac{\text { Sugen-hypoxia-induced PAH }}{\text { Treatments }}$} \\
\hline & & Vehicle & $\begin{array}{c}\text { RP5063 } \\
10 \mathrm{mg} / \mathrm{kg} \text { BID }\end{array}$ & $\begin{array}{c}\text { RP5063 } \\
20 \mathrm{mg} / \mathrm{kg} \text { BID }\end{array}$ & $\begin{array}{c}\text { Sildenafil } \\
50 \mathrm{mg} / \mathrm{kg} \text { BID }\end{array}$ \\
\hline Diastolic pulmonary pressure (mmHg) & 12.3 & 17.0 & 15.3 & 14.7 & 13.8 \\
\hline Systolic pulmonary pressure (mmHg) & 25 & 43.0 & 32.2 & 32.0 & 31.8 \\
\hline Mean pulmonary pressure (mmHg) & 16.5 & 25.7 & 20.9 & 20.4 & 19.8 \\
\hline Oxygen saturation (\%) & 95.9 & 93.8 & 95.9 & 96.9 & 97.0 \\
\hline Fulton's index & 0.2 & 0.4 & 0.3 & 0.4 & 0.3 \\
\hline Small vessel wall thickness (\%) & 16.2 & 42.8 & 34.3 & 23.7 & 17.2 \\
\hline Presence of vascular smooth muscle (\%) & 9.5 & 83.3 & 62.6 & 39.9 & 28.0 \\
\hline
\end{tabular}


thickening of the pulmonary arteries due to $5-\mathrm{HT}_{2 \mathrm{~B}}$ induced by BW723C86 in rats ${ }^{17}$.

\section{Beyond 5-HT Modulation: Cytokine/Chemokine Effects}

Inflammation is characteristic of $\mathrm{PAH}$, and elevated plasma levels of cytokines/chemokines are reported in patients with idiopathic $\mathrm{PAH}^{19}$. In addition to its effects on 5-HT biology, exploratory evidence suggests that RP5063 may facilitate a marked downregulation of chemokines and inflammatory cytokines. Both studies included an exploratory evaluation of the effect of RP5063 on cytokines and chemokines. In the MCT study, a model considered to be representative of idiopathic PAH and involves an early inflammatory phase, all doses of RP5063 (vs MCT+Veh) reflected lower levels of the proinflammatory cytokines, TNF- $\alpha$, IL- $\beta$, and IL- 6 , over the final 2 weeks of treatment (Figure 1). Only RP-10 produced a significant effect on IL-6 levels $(\mathrm{p}<0.05)$. By contrast, the SuHx study is generally considered a predictive model for Group 3 PAH (i.e., PAH resulting from lung disease ${ }^{20}$. In this study, which did not exhibit a significant inflammatory component, RP5063 did not produce any significant changes in these inflammatory cytokines. However, notable, yet not statistically significant changes were seen in LT-B4 levels. Both doses of RP5063 prevented the release of LT-B4 to less than half the plasma level measured in untreated animals on Day 21. This effect persisted until Day 28 in animals treated with 10 and 20 $\mathrm{mg} / \mathrm{kg} /$ day RP5063 and to Day 35 in the RP-20 group ${ }^{3}$.

Inflammation is a feature of $\mathrm{PAH}$, particularly in cases of idiopathic disease. Studies reflect that inflammatory cytokines (e.g., monocyte chemoattractant protein 1 , TNF- $\alpha$, IL- $\beta$, IL-6) play a role in idiopathic PAH development, particularly in the vascular cell proliferation and remodeling of the pulmonary arteries ${ }^{19,21-23}$. One analysis reports that IL-6, IL-8, IL-10, and IL-12p70 can predict PAH patients' survival ${ }^{19}$. In $\mathrm{PAH}$, pathologic specimens show that perivascular inflammatory cells (e.g., macrophages, dendritic cells, $\mathrm{T}$ and B lymphocytes, mast cells) accumulate due to the increased levels of cytokines and chemokines ${ }^{23}$. Furthermore, another evaluation indicated that LT-B4 causes pulmonary vascular remodeling in PAH by directly injuring luminal endothelial cells, promoting the growth of the smooth muscle cell layer of pulmonary arterioles, and enhancing human pulmonary artery adventitial fibroblast proliferation, migration, and differentiation in a dose-dependent manner through its cognate G-protein-coupled receptor, BLT124. LT-B4 is also a mediator of pulmonary inflammation and contributes to pulmonary vascular remodeling ${ }^{25}$.

The observed effects of RP5063 on proinflammatory cytokines and LT-B4 suggest that an additional mechanism might play a role in the structural and functional changes related to PAH. This mechanism could be influenced by modulation of the pulmonary arterial $5-\mathrm{HT}_{7}$, in addition to $5-\mathrm{HT}_{2 \mathrm{~A} / 2 \mathrm{~B}}$ receptors. In particular, antagonizing the $5-\mathrm{HT}_{2 \mathrm{~A} / 2 \mathrm{~B} / 7^{-}}$receptors can suppress pulmonary vessel smooth muscle inflammatory histopathologic changes and proliferation, reduce inflammatory cytokines, and inhibit pulmonary vasoconstriction ${ }^{14,26-28}$. Amelioration of MCTinduced increases in inflammatory cytokines (e.g., IL-1 $\beta$, IL-6, TNF- $\alpha$, monocyte chemoattractant protein 1), along with associated inflammatory histopathologic changes in muscularization and medial wall thickness in the pulmonary vascular smooth muscle, were seen with antagonism of $5-\mathrm{HT}_{2 \mathrm{~A} / 2 \mathrm{~B}}$ receptors by terguride ${ }^{14}$. Hence, the modulation of these factors may offer a complementary mechanism that could influence tissue remodeling and other clinical sequelae. This additional action would make RP5063 an attractive, possibly disease-modifying adjunct to present treatment strategies. Nevertheless, because these initial evaluations are exploratory, further work is needed to fully elucidate the impact of RP5063 on these cytokines/ chemokines and the role that $5-\mathrm{HT}_{2 \mathrm{~A} / 2 \mathrm{~B} / 7}$ modulation plays in mitigating the release of these factors.

\section{Model Differences Provide Further Insight}

The MCT and SuHx models provided mutually supportive evidence that modulating 5 -HT activity is efficacious in the mitigation of the physiopathology of PAH, and that RP5063 is effective at influencing the structural and functional end points seen with PAH induced in rats. In addition to fundamental differences in the study designs, the models themselves are complementary in many ways, and thus did not necessarily replicate the same outcomes.

Treatment in the MCT study started on Day 0 and continued for 4 weeks; by contrast, the SuHx study treatment started 2 weeks after induction and continued for 3 additional weeks. This delay might have allowed the PAH process to become more established, thereby limiting the clinical benefits of the treatment. Hence, treatment in the MCT model played more of a preventive role, whereas treatment in the SuHx model functioned more to remedy the established structural and functional changes.

A further explanation may be inherent to the $2 \mathrm{PAH}$ models. MCT-induction in rats, one of the classic models of $\mathrm{PAH}$, is characterized by acute/subacute damage to the peripheral arteries ${ }^{29-31}$. It has been widely used in evaluating more than 30 agents $^{31}$. In the model, MCT causes direct endothelial damage, thereby triggering the development and progression of severe and eventually lethal $\mathrm{PAH}^{32}$. Following the administration of MCT, the onset of increased pulmonary arterial pressure and vascular remodeling is delayed from 1 to 2 weeks $^{33}$. These effects appear to be due to the early and dramatic accumulation of mononuclear inflammatory cells in the adventitial sheath of the small intra-acinar vessels, an important event in the pathogenesis of PAH that occurs in the pulmonary arteries and veins and precedes any smooth muscle hypertrophy in 
the media ${ }^{34}$. MCT-induced PAH is progressive in laboratory animals, and generally severe; however, in this model, there is no formation of an obstructive intimal lesion in the peripheral pulmonary arteries ${ }^{31}$.

By contrast, the SuHx model produces a milder form of PAH, as an alternative to the MCT and chronic hypoxia models. It was established to address the etiologic mechanisms involved in the endothelial cell hyperproliferation that characterizes the plexogenic arteriopathy or the obstructive intimal lesion (i.e., plexiform lesions) in the peripheral pulmonary arteries seen in human $\mathrm{PAH}^{29,31}$. It is based on the concept that vascular endothelial growth factor is an important maintenance and differentiating factor for vascular endothelial cells. In chronically hypoxic rats, Sugen 5416, a vascular endothelial growth factor receptor inhibitor, causes severe, irreversible PAH with intimal lesions characterized by precapillary, small-vessel arterial endothelial proliferations ${ }^{35}$. In this model, vascular endothelial growth factor receptor blockade and chronic hypoxia result in these lesions and persistent, progressive PAH, and thereby lead to RV remodeling and failure, even after the hypoxic stimulus is removed ${ }^{35}$.

Many treatments (e.g., antineoplastics, angiotensinconverting enzyme inhibitors, angiotensin 2 inhibitors, type 1 receptor blockers, bradykinin antagonists, antiangiogenic agents, peroxisome proliferator-activated receptor agonists, calcium channel blockers), either as monotherapy or in combination, do not fully reverse the progression of $\mathrm{PAH}$, vis-à-vis the functional and structural aspects of the disease in these preclinical models ${ }^{31}$.
Therefore, a complete reversal of the symptoms of PAH in either model is not expected. An amelioration of specific parameters (e.g., right-ventricular remodeling, limited arterial obliteration, and the successful prevention of the formation of plexiform lesions) represent exciting benefits that may translate in the clinic.

As a result, the observations from these 2 models must be interpreted based on these differences, along with the previously discussed variations in the treatment regimens. However, the most important consideration here is that both models displayed treatment-responsive structural effects following the induction and development of $\mathrm{PAH}$, and that known mechanisms of 5-HT modulation support the observed benefits in pathological preclinical models. In the light of the differences between the models, and their complementarities, a drug that shows robust efficacy in both MCT and SuHx models has the best likelihood of being efficacious against clinical PAH.

\section{New Combination Therapy Enhances Monothera- py Results}

Based on the initial performance of RP5063 as a singleagent treatment in both the MCT and SuHx models in rats, an additional study was undertaken with this compound to evaluate its role in combination therapy ${ }^{36}$. In the same MCT model as previously described, RP5063 was subsequently evaluated both as monotherapy and as an adjunct to current standards of PAH care (bosentan, sildenafil, treprostinil).

The observations with RP5063 as a single agent were consistent with the previous MCT study in limiting the functional and structural effects (Figure 2) seen in the

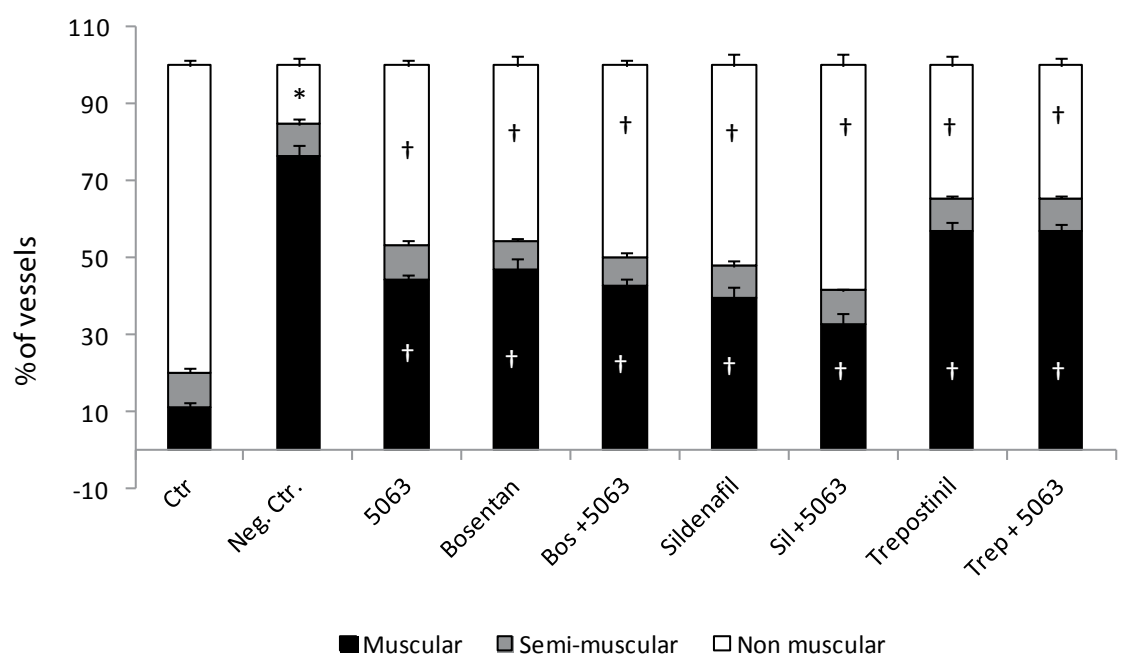

Figure 2. Small vessel remodeling in MCT-induced PAH

Morphometric analysis was conducted to quantify the remodeling observed in small, medium, and large pulmonary arteries. PAH is associated with vascular smooth muscle hyperplasia and hypertrophy, which translates into vessel "muscularization," loss of luminal space, and hindered blood flow. The percent of muscularized vessels went varies from approximately $10 \%$ in healthy animals, to approximately $75 \%$ in sick animals. RP5063 alone, and in combination with various current standards of care for PAH, significantly reduced the smooth muscle remodeling. Except for a combination with treprostinil, RP5063 was able to provide an additive effect against pulmonary vascular remodeling. 
MCT+Veh group and were similar to (and in some cases better than) the standard treatments. As an adjunct to all treatments, however, RP significantly $(p<0.05)$ lowered mean and systolic pulmonary artery pressures and RV systolic pressure, and improved oxygen saturation when compared with sick, untreated animals. Its combination with sildenafil reflected the most consistent and robust effects on pulmonary hemodynamics, respiratory parameters, and histopathologic changes ${ }^{36}$.

These observations are significant because the MCT and SuHx models have been used for evaluating the preclinical efficacy for PAH with a variety of investigational and approved treatments, including the combination of two approved drugs from different mechanism of actions ${ }^{31,37-40}$. Furthermore, efficacy data demonstrated by multiple approved drugs in these preclinical models clearly support clinical translation, and highlight a defined regulatory and clinical development path besides providing their valuable clinical data.

Presently approved therapy involves a single, or a combination of, 3 core strategies: $1-$ increasing nitric oxide via phosphodiesterase type 5 inhibition (e.g., sildenafil); 2- antagonizing endothelin (e.g., bosentan); and 3- providing exogenous prostacyclins (e.g., epoprostenol, iloprost, treprostinil $)^{41-44}$. Present treatment strategies focus on addressing smooth muscle tone to enhance dilation to improve hemodynamics, symptoms, exercise tolerance, quality of life, functionality, and survival. Unfortunately, these approaches fall short of limiting the ongoing cytoproliferative processes that lead to pulmonary vascular structure modification and disease progression ${ }^{6}$.

PAH patients are treated with monotherapy from a very early stage of the disease. As PAH progresses, patients are treated with combinations of 2 or 3 approved drugs from different classes ${ }^{45}$. One analysis noted that approximately $56 \%$ of patients were taking additional therapy within 2 years of their initial diagnosis ${ }^{46}$. The combination treatment provides additive vasodilation effect through different mechanisms of action. Unfortunately, present combination strategies have yet to yield consistent clinical results for a few reasons, among them: 1 - currently targeted pathways overlap $^{47,48}$, and 2- patients usually initiate vasodilator combination therapy after the disease has progressed to the extent that pulmonary vascular and right-ventricular remodeling are significant, with fibrosis often present in later stages of the disease, leading to less hemodynamic benefits than would be expected based on the potency of the vasodilators used.

Hence, the observed effects of RP5063 in combination with standard treatments, and in particular with sildenafil, are encouraging. RP5063 receptor profile indicates that it will exert an antifibrotic/antiproliferative $\left(5-\mathrm{HT}_{2 \mathrm{~B}}\right)$, vasorelaxation $\left(5-\mathrm{HT}_{2 \mathrm{~A}}\right)$ and anti-inflammatory effects (5- $\mathrm{HT}_{7}$ ) due to the compound's potent interaction with the $5-\mathrm{HT}_{2 \mathrm{~A} / 2 \mathrm{~B} / 7}$ receptors ${ }^{10,14,16-18}$. Thus, combination treatment of RP5063 with other approved drugs may provide for improved vasorelaxation due to additive effects besides structural modification caused on antifibrotic and antiproliferative effects. This profile offers promise for delaying the progressing of the disease, which naturally would need to be born out in the clinic. To this end, RP5063 was granted orphan status by the US Food and Drug Administration as a potential treatment of PAH and most likely will be explored in combination with sildenafil ${ }^{49}$.

\section{Conclusion}

Due to the present survival rates with $\mathrm{PAH}$ and the challenges with current treatment strategies, a tremendous unmet need exists in the management of this condition. The published reports of the preclinical experience with RP5063 in the MCT and SuHx models, both as single-agent and in combination with standard treatments, reinforce the notion that combining various treatment with synergistic mechanisms of action will produce unparalleled efficacy in the treatment of clinical PAH.

With a novel mechanism of action involving the modulation of 5-HT, RP5063 may represents the first of a new series of therapeutics targeting not-only smooth muscle constriction, but also additional causes of PAH remodeling and inflammation. It is interesting that this compound, originally destined for the management of schizophrenia, offers unique potential for PAH. RP5063 may be equally efficacious in psychiatric and cardiopulmonary conditions such as $\mathrm{PAH}$, a condition in which $35 \%$ of patients experience some type of comorbid mental disorder, based on the roles of 5-HT as a neurotransmitter and mitogen, respectively ${ }^{50,51}$. Just as significant may be the potential of addressing PAH not only via a direct interaction with the $5-\mathrm{HT}_{2 \mathrm{~A} / 2 \mathrm{~B} / 7}$ receptors, but also -in parallel- through stemming proinflammatory cytokine and chemokine release induced by a pathologic stimulant. The effects of RP5063 on limiting arterial obliteration and preventing plexiform lesions in the SuHx model, along with its structural and cytokine/chemokine effects, suggest that it targets major factors contributing to PAH pathogenesis and could offer clinicians a disease-modifying approach to PAH. The imminent initiation of a Phase 2 investigation in humans will assess whether these promising findings in the current gold-standard preclinical models will translate into a clinical reality.

\section{Acknowledgments and Disclosures}

\section{Funding Support}

RP5063 studies discussed in this review were 
supported by a grant to IPS Therapeutique, Inc., from Reviva Pharmaceuticals., Inc.

\section{Editorial Support}

Editorial support was provided by John M. York, PharmD, MBA. This assistance was funded by Reviva Pharmaceuticals, Inc.

\section{Disclosures}

- Laxminarayan Bhat, $\mathrm{PhD}$, is an employee of Reviva Pharmaceuticals, Inc.

- Dany Salvail, PhD, is an employee of IPS Therapeutique, Inc.

\section{References}

1. Cantillon M, Prakash A, Alexander A, et al. Dopamine Serotonin Stabilizer RP5063: A Randomized, Double-blind, Placebo-controlled Multicenter Trial of Safety and Efficacy in Exacerbation of Schizophrenia or Schizoaffective Disorder. Schizophrenia Research. 2017. doi: 10.1016/j.schres.2017.01.043. [Epub ahead of print].

2. Bhat L, Hawkinson J, Cantillon M, et al. RP5063, a novel multimodal serotonin receptor modulator prevents monocrotaline-induced pulmonary arterial hypertension in rats. Eur J Pharmacol. 2017; 810: 92-99.

3. Bhat L, Hawkinson J, Cantillon M, et al. RP5063 a novel multimodal serotonin receptor modulator prevents Sugen 5416-hypoxia-induced pulmonary arterial hypertension in rats. Eur J Pharmacol. 2017; 810: 83-91.

4. Peacock AJ, Murphy NF, McMurray JJ, et al. An epidemiological study of pulmonary arterial hypertension. Eur Resp J. 2007; 30(1):104-9.

5. Benza RL, Miller DP, Barst RJ, et al. An evaluation of long-term survival from time of diagnosis in pulmonary arterial hypertension from the REVEAL Registry. Chest. 2012; 142 (2): 448-56.

6. Zopf DA, das Neves LAA, Nikula KJ, et al. C-122 a novel antagonist of serotonin receptor 5-HT2B prevents monocrotaline-induced pulmonary arterial hypertension in rats. Eur J Pharmacol. 2011; 670: 195-203.

7. Constantinides P, Robinson M. Ultrastructural injury of arterial endothelium 3 effects of enzymes and surfactants. Archives of Pathology. 1969; 88(2): 113-117.

8. Sirek A, Sirek OV. Serotonin a review. Can Med Assoc J. 1970; 102: 846-849.

9. Esteve JM, Launay JM, Kellermann 0, et al. Functions of serotonin in hypoxic pulmonary vascular remodeling. Cell Biochem Biophys. 2007; 47: 33-43.

10. West JD, Carrier EJ, Bloodworth NC, et al. Serotonin 2B Receptor Antagonism Prevents Heritable Pulmonary Arterial Hypertension. PLOSOne. 2016; 11(2): 1-18.

11. Baliga RS, MacAllister RJ, Hobbs AJ. New perspectives for the treatment of pulmonary hypertension. Br J Pharmacol. 2011; 163(1): 125-140.

12. MacLean MR, Dempsie Y. The serotonin hypothesis of pulmonary hypertension revisited. Adv Exp Med Biol. 2010; 661: 309-322.

13. Shacham S, Orbach P, Marantz Y, et al. PRX-08066: A Potent 5-HT2B Receptor Antagonist with a dual disease modifying/vasodilating mechanism for the Treatment of Pulmonary Hypertension. 2006 International PHA Conference and Scientific Sessions. Minneapolis, MN, June 23-25, 2006. Abstract: 32. Accessed at: http://www.phaonlineuniv. org/ResourceLibrary/Resource.cfm?ItemNumber=3932. Access date: November 26, 2016.
14. Dumitrascu R, Kulcke C, Königshoff M, et al. Terguride ameliorates monocrotaline induced pulmonary hypertension in rats. Eur Respir J. 2011; 37: 1104-1118.

15. Farber HW, Loscalzo J. Pulmonary Artery Hypertension. N Engl J Med. 2004; 351(16): 1655-65.

16. Welsh DJ, Harnett J, MacLean M, et al. Proliferation and signaling in fibroblasts: role of 5-hydroxytryptamine ${ }_{2 \mathrm{~A}}$ receptor and transporter. Am J Respir Crit Care Med. 2004; 170: 252-259.

17. Liu Y, Tian XY, Mao G. Peroxisome ameliorates pulmonary arterial hypertension by inhibiting 5-hydroxytryptamine $2 \mathrm{~b}$ receptor. Hypertension. 2012; 60: 1471-1478.

18. Porvasnik SL, Germain S, Embury J, et al. PRX-08066, a novel 5-hydroxytryptamine receptor 2B (5-HT2B) receptor antagonist, reduces monocrotaline-induced pulmonary arterial hypertension and right ventricular hypertrophy in rats. J Pharmacol Exp Ther. 2010; 334(2): 364-72.

19. Soon E, Holmes AM, Treacy TM, et al. Elevated Levels of Inflammatory Cytokines Predict Survival in Idiopathic and Familial Pulmonary Arterial Hypertension. Circulation. 2010; 122: 920-927.

20. Simonneau G, Gatzoulis MA, Adatia I, et al. Updated clinical classification of pulmonary hypertension. J Am Coll Cardiol. 2013 24; 62(25 Suppl): D34-41.

21. Humbert M, Monti G, Brenot $\mathrm{F}$, et al. Increased interleukin-1 and interleukin-6 serum concentrations in severe primary pulmonary hypertension. Am J Respir Crit Care Med. 1995; 151: 1628-1631.

22. Itoh $\mathrm{T}$, Nagaya $\mathrm{N}$, Ishibbashi Ueda $\mathrm{H}$, et al. Increased plasma monocyte chemoattractant protein-1 level in idiopathic pulmonary arterial hypertension. Respirology. 2006; 11: 158-163.

23. Prince LC, Wort SJ, Perros F, et al. Inflammation in Pulmonary Arterial Hypertension. Chest. 2012; 141(1): 210-221.

24. Quan J, Tian W, Jiang X, et al. Leukotriene B4 Activates Pulmonary Artery Adventitial Fibroblasts in Pulmonary Hypertension. Hypertension. 2015; 66: 1227-1239.

25. Tian W, Jiang X, Sung YK, et al. Leukotrienes in pulmonary arterial hypertension. Immunol Res. 2014; 58: 387-393.

26. Ayaz G, Halici Z, Albayrak A, et al. Evaluation of 5-HT7 Receptor Trafficking on In Vivo and In Vitro Model of Lipopolysaccharide (LPS)Induced Inflammatory Cell Injury in Rats and LPS-Treated A549 Cells. Biochem Genet. 2017; 55(1): 34-47.

27. Cadirci E, Halici Z, Bayir Y, et al. Peripheral 5-HT7 receptors as a new target for prevention of lung injury and mortality in septic rats. Immunobiology. 2013; 218 (10): 1271-1283.

28. Jähnichen S, Glusa E, Pertz HH. Evidence for 5-HT2B and 5-HT7 receptor-mediated relaxation in pulmonary arteries of weaned pigs. Naunyn Schmiedebergs Arch Pharmacol. 2005; 371(1): 89-98.

29. Gomez-Arroyo J, Nikolic I, Yu PB. Animal Models of Pulmonary Hypertension, in: Maron B.A., Zamamian R., Waxman A.B. (Eds.), Pulmonary Hypertension: Basic Science to Clinical Medicine. Springer Inc New York. 2016; pp. 17-28.

30. Lalich JJ, Johnson WD, Raczniak TH, et al. Fibrin thrombosis in 620 monocrotaline tyrrole-induced cor pulmonale in rats. Arch Pathol Lab Med. 1977; 621: 69-73.

31. Stenmark KR, Meyrick B, Galie NG, et al. Animal models of pulmonary arterial hypertension: the hope for etiological discovery and pharmacological cure. Am J Physiol Lung Cell Mol Physiol. 2009; 297: L1013-L1032.

32. Jasmin JF, Lucas M, Cernacek $P$, et al. Effectiveness of a nonselective ET(A/B) and a selective ET(A) antagonist in rats with monocrotalineinduced pulmonary hypertension. Circulation. 2001; 103(2): 314318. 
33. Meyrick B, Gamble W, Reid L. Development of Crotalaria pulmonary hypertension: hemodynamic and structural study. Am J Physiol. 1980; 239(5): H692-702.

34. Wilson DW, Segall HJ, Pan LC, et al. Progressive inflammatory and structural changes in the pulmonary vasculature of monocrotalinetreated rats. Microvasc Res. 1989; 38: 57-80.

35. Taraseviciene Stewart L, Kasahara Y, Alger L, et al. Inhibition of the VEGF receptor 2 combined with chronic hypoxia causes cell deathdependent pulmonary endothelial cell proliferation and severe pulmonary hypertension. FASEB J. 2001; 15: 427-438.

36. Bhat L, Hawkinson J, Cantillon M, et al. Evaluation of the effects of RP5063, a novel, multimodal, serotonin receptor modulator, as single-agent therapy and co-administrated with sildenafil, bosentan, and treprostinil in a monocrotaline-induced pulmonary arterial hypertension rat model. Eur J Pharmacol. 2017. (Submitted).

37. Rafikova O, Rafikov R, Kumar S, et al. Bosentan inhibits oxidative and nitrosative stress and rescues occlusive pulmonary hypertension. Free radical biology \& medicine. 2013; 56: 28-43.

38. Rashid J, Patel B, Nozik Grayck E, et al. Inhaled sildenafil as an alternative to oral sildenafil in the treatment of pulmonary arterial hypertension (PAH). J Control Release. 2017; 250: 96-106.

39. van Albada ME, van Veghel R, Cromme Dijkhuis AH, et al. Treprostinil in advanced experimental pulmonary hypertension: beneficial outcome without reversed pulmonary vascular remodeling. J Cardiovasc Pharmacol. 2006; 48(5): 249-54.

40. Clozel M, Hess P, Rey M, et al. Bosentan, sildenafil, and their combination in the monocrotaline model of pulmonary hypertension in rats. Exp Biol Med (Maywood). 2006; 231(6): 967-73.

41. Corbin JD, Beasley A, Blount MA, et al. High lung PDE5: a strong basis for treating pulmonary hypertension with PDE5 inhibitors. Biochem Biophys Res Commun. 2005; 334: 930-938.
42. Christman BW, McPherson CD, Newman JY, et al. An imbalance between the excretion of thromboxane and prostacyclin metabolites in pulmonary hypertension. N Engl J Med. 1992; 327: 70-75.

43. Galiè N, Manes A, Branzi A. The endothelin system in pulmonary arterial hypertension. Cardiovasc Res. 2004; 61: 227-237.

44. Humbert M, Sitbon O, Simonneau G. Treatment of pulmonary arterial hypertension. N Engl J Med. 2004; 351: 1425-1436.

45. Bishop BM, Mauro VF, Khouri SJ. Practical considerations for the pharmacotherapy of pulmonary arterial hypertension. Pharmacotherapy. 2012; 32(9): 838-55.

46. Provencher S, Sitbon 0 , Humbert M, et al. Long-term outcome with first-line bosentan therapy in idiopathic pulmonary arterial hypertension. Eur Heart J. 2006; 27: 89-95.

47. Gruenig E, Michelakis E, Vachiéry JL, et al. Acute hemodynamic effects of single-dose sildenafil when added to established bosentan therapy in patients with pulmonary arterial hypertension: results of the COMPASS-1 study. J Clin Pharmacol. 2009; 49(11) : 1343-1352.

48. Galie N, Hoeper MM, Humbert M, et al. Guidelines for the diagnosis and treatment of pulmonary hypertension: The Task Force for the Diagnosis and Treatment of Pulmonary Hypertension of the European Society of Cardiology (ESC) and the European Respiratory Society (ERS), endorsed by the International Society of Heart and Lung Transplantation (ISHLT). Eur Heart J. 2009; 30(20): 2493-537.

49. Henriques C. Lung Disease News., Dallas, Texas: BioNews Services, LLC; November 21, 2016 Available from: https://lungdiseasenews. com/2016/11/21/reviva-receives-fda-orphan-drug-designation-forpulmonary-arterial-hypertension-psychosis-treatment/.

50. Lowe B, Gräfe K, Ufer C, et al. Anxiety and depression in patients with pulmonary hypertension. Psychosom Med. 2004; 66: 831-836.

51. Verma S, Sahni S, Vijayan VK, et al. Depression in pulmonary arterial hypertension an undertreated comorbidity. Lung India. 2016; 33(1): $58-63$. 